\title{
PENERAPAN HACCP DALAM PROSES PRODUKSI MENU DAGING RENDANG DI INFLIGHT CATERING
}

\author{
Implementation of HACCP in Beef Rendang Production at Inflight Catering
}

\author{
Ardanisworo Lintang Wicaksani' ${ }^{1}$, Retno Adriyani ${ }^{2}$ \\ ${ }^{1}$ Program Studi S1 Ilmu Gizi, Fakultas Kesehatan Masyarakat, Universitas Airlangga, Surabaya \\ ${ }^{2}$ Departemen Kesehatan Lingkungan, Fakultas Kesehatan Masyarakat, Universitas Airlangga, Surabaya \\ Email:lintangwicaksani17@gmail.com
}

\begin{abstract}
ABSTRAK
Hazard Analysis Critical Control Point (HACCP) merupakan salah satu sistem keamanan pangan dengan cara analisis terhadap bahan, proses, dan produk pangan. Analisis HACCP dapat digunakan sebagai upaya pengawasan kualitas produk akhir agar memenuhi syarat produk makanan yang sehat, aman, dan halal. PT X merupakan perusahaan catering untuk pengguna layanan pesawat terbang (inflight catering). Perusahaan ini telah menerapkan HACCP dalam setiap produksi makanan. Jenis penelitian ini adalah deskriptif dengan metode observasi pada proses produksi menu daging rendang. Penerapan HACCP dalam proses produksi menu daging rendang di PT.X adalah dengan mengontrol suhu dan waktu selama proses produksi untuk mencegah pertumbuhan mikroba dalam makanan. Dari sepuluh penerapan HACCP menurut SNI No. 01-4852-1998 tentang sistem HACCP hanya satu poin penerapan saja yang belum sesuai dengan SNI, yaitu pada monitoring. Kegiatan monitoring tidak dilakukan secara rutin saat proses blast chilling dan dishing. Potongan kemasan santan masuk ke dalam panci ketika proses pemasakan karena pemotongan kemasan santan dilakukan di atas panci pemasak. Sembilan penerapan HACCP yang lainnya yaitu penetapan tim HACCP, deskripsi produk, pembuatan diagram alir, identifikasi bahaya, penentuan titik kritis, penentuan batas kritis tiap CCP, tindakan koreksi, verifikasi mikrobiologi, dan dokumentasi telah diterapkan sesuai dengan SNI.
\end{abstract}

Kata kunci: HACCP, inflight catering, rendang daging

\begin{abstract}
HACCP is one of the food safety systems which is done by analyzing materials, processes, and food products. HACCP analysis can be used as an effort to control the quality of the final product in order to meet the requirements of healthy, safe and halal food products. PT X is a catering company for aircraft service users (inflight catering). This company has implemented HACCP in every food production. This is a descriptive research by observing the process of rendang meat production. The application of HACCP in PT. X is done by controlling temperature and time during production process to prevent microbes growth. From ten application of HACCP according to SNI No. 01-4852-1998 about HACCP there is a point that has not been accordance with SNI monitoring. Monitoring activities are not routinely performed on blast chilling and dishing process. Pieces of coconut milk's pack fall in to the pan when cooking process because the cutting of coconut milk pack is done on the cooking pan. Other HACCP principles like HACCP team determination, product description, flow chart reaction, hazard identification, critical point determination, critical boundary determination of each CCP, corrective action, microbiological verification, and documentation are well implemented.
\end{abstract}

Keywords: HACCP, inflight catering, beef rendang

\section{PENDAHULUAN}

Pertumbuhan ekonomi dunia yang semakin meningkat disertai pula dengan mobilitas masyarakat yang semakin tinggi. Pada tahun 2010, PT. Angkasa Pura II menyatakan adanya peningkatan penumpang pesawat pada seluruh bandara yang dikelolanya secara signifikan, yaitu sebesar 10,3\%. Pada penerbangan dengan jarak tempuh cukup jauh, pihak maskapai menyediakan makanan bagi penumpang dan awak.

Perusahaan pengolahan makanan harus menjamin kualitas produknya agar layak dan aman 
dikonsumsi oleh konsumen. Keamanan Pangan (food safety) menurut Peraturan Pemerintah Republik Indonesia Nomor 28 Tahun 2004 tentang keamanan, mutu dan gizi pangan adalah kondisi dan upaya yang diperlukan untuk mencegah pangan dari kemungkinan cemaran biologis, kimia dan benda lain yang dapat mengganggu, merugikan, dan membahayakan kesehatan manusia.

Industri katering, termasuk inflight catering mempunyai risiko penularan penyakit melalui makanan (foodborne disease) yang tinggi jika penanganan makanannya tidak dilakukan dengan baik (Handayani, 2012). Rendang merupakan salah satu makanan khas Padang yang banyak digemari masyarakat dan terbuat dari bahan yang berpotensi tercemar secara biologis, kimia, dan fisik (Puspitasari, 2015). Menu daging rendang menjadi menu yang diproduksi dalam jumlah besar oleh PT. X karena permintaan dari maskapai pemesan tinggi. Di sisi lain, bahan pangan asal ternak seperti daging serta olahannya merupakan media pertumbuhan yang sangat baik bagi mikroba, sehingga mudah rusak. Pengolahan yang benar dapat menekan pertumbuhan mikroba tersebut (Gustiani, 2009).

Sumber kontaminasi yang potensial yaitu penjamah makanan, peralatan pengolahan dan peralatan makan, serta adanya kontaminasi silang (Ratnaningsih, 2010). Kontaminasi mikrobiologi pada industri katering penerbangan dapat mengakibatkan keracunan pada penumpang pesawat. Masalah ini menjadi sangat serius jika keracunan terjadi saat pesawat berada jauh dari bandara sehingga tidak terjangkau oleh pelayanan medis (Fitriana, 2012). Kasus keracunan makanan pada penumpang pesawat terjadi pada tahun 2013 yang menimpa penumpang China Air setelah makan pancake yang disediakan pesawat. Tahun 2016, penumpang Air Asia rute Kuala Lumpur- Serawak menemukan adanya bangkai cicak di dalam makanan nasi lemak di pesawat (Huda, 2016).

Sistem keamanan pangan seperti HACCP (Hazard Analysis Critical Control Point) diperlukan untuk menjamin produk aman dari potensi bahaya. HACCP merupakan suatu sistem pengawasan untuk mencegah kemungkinan terjadinya keracunan atau foodborne disease. HACCP meliputi analisis bahaya dan pengendalian titik kritis untuk menjamin produk yang dikonsumsi aman dari bahaya fisik, kimia (pestisida), dan mikrobiologi (Dewi, 2015). Konsep HACCP dapat diterapkan dalam seluruh proses pengolahan makanan. Aplikasi HACCP pada umumnya dilakukan dengan analisis kendali kritis pada proses penerimaan bahan baku, proses produksi, sampai dengan penyimpanan sebelum produk dipasarkan (Sadek, 2010).

\section{METODE}

Penelitian ini dilakukan di bagian inflight catering PT X yang berlokasi di Surabaya dengan jenis penelitian evaluatif dengan metode observasi terhadap proses produksi menu daging rendang. Hasil observasi dideskripsikan dalam bentuk narasi, tabel, dan diagram alir. Hasil penelitian dianalisis dengan membandingkan proses produksi menu daging rendang dengan SNI No. 01-4852-1998 tentang sistem analisis bahaya dan pengendalian titik kritis (HACCP) serta pedoman penerapannya.

\section{HASIL DAN PEMBAHASAN}

PT. X telah menerapkan sistem keamanan pangan HACCP dalam setiap produksinya. Penerapan HACCP dalam proses produksi inflight catering menu daging rendang meliputi 10 langkah penerapan dengan 7 prinsip HACCP. Langkah penerapan HACCP adalah penetapan tim HACCP, deskripsi produk, penentuan diagram alir, identifikasi bahaya, penentuan Critical Control Point (CCP), penetapan batas kritis tiap $\mathrm{CCP}$, monitoring, tindakan koreksi, verifikasi mikrobiologi, dan dokumentasi.

\section{Penetapan tim HACCP}

Susunan tim HACCP di PT. X adalah sebagai berikut :

Manajer

Manajer K3LH

: Ketua umum

Manajer Produksi

: Anggota I

Manajer Operasional

Kepala Teknisi

: Anggota II

Manajer SDM

: Anggota III

: Anggota IV

: Anggota $\mathrm{V}$

Manajer Rumah Tangga : Anggota VI 
Susunan tim HACCP sesuai dengan pernyataan Afrianto (2008) yang mengatakan bahwa tim HACCP terdiri dari berbagai disiplin ilmu. Anggota tim HACCP adalah individu yang berkompeten di bidang teknik, produksi, sanitasi, jaminan kualitas, dan mikrobiologi makanan. Pelibatan para manajer sebagai orang yang paling berpengaruh ke dalam tim HACCP ini dapat meningkatkan kesadaran penerapan HACCP secara menyuluruh. Hal ini sudah sesuai dengan SNI No. 01-4852-1998. Tim HACCP melibatkan semua komponen yang terlibat dalam produksi pangan yang aman (Handayani, 2012).

\section{Deskripsi produk}

Deskripsi menu daging rendang adalah sebagai berikut:

\begin{tabular}{ll}
\hline Nama produk & Daging rendang \\
\hline Komposisi & $\begin{array}{l}\text { Daging sapi, bumbu rendang } \\
\text { instan (dengan komposisi: } \\
\text { lengkuas, kunyit, jahe, cabe, } \\
\text { bawang merah, bawang putih), } \\
\text { penyedap rasa / monosodium } \\
\text { glutamate (MSG), santan, } \\
\text { garam, minyak, air. }\end{array}$ \\
\hline $\begin{array}{l}\text { Penggunaan } \\
\text { produk }\end{array}$ & $\begin{array}{l}\text { Dipanaskan lagi jika akan } \\
\text { dikonsumsi }\end{array}$ \\
\hline Kemasan & $\begin{array}{l}\text { Dikemas dalam aluminium foil, } \\
\text { plate, china ware dan box yang } \\
\text { disediakan airline. }\end{array}$ \\
\hline $\begin{array}{l}\text { Metode } \\
\text { pengawetan }\end{array}$ & $\begin{array}{l}\text { Pendinginan dan pembekuan } \\
\text { Konsumen }\end{array}$ \\
\hline $\begin{array}{l}\text { Masyarakat umum khusus } \\
\text { penumpang pesawat, } \\
\text { penumpang yang membutuhkan } \\
\text { makanan khusus }\end{array}$ \\
\hline $\begin{array}{l}\text { Instruksi pada } \\
\text { label }\end{array}$ & $\begin{array}{l}\text { Widak ada } \\
\text { Wemasakan hingga portioning } \\
\text { adalah 48 jam. Waktu maksimal } \\
\text { dari portioning hingga delivery } \\
\text { adalah 24 jam. }\end{array}$ \\
\hline Usia simpan
\end{tabular}

\begin{tabular}{ll}
\hline & $\begin{array}{l}\text { Makanan yang telah dikemas } \\
\text { ditempatkan pada tray dan } \\
\text { dimasukkan di dalam holding }\end{array}$ \\
Metode & chiller kemudian diisi dengan \\
distribusi & dryice bila akan dikirim ke \\
& pesawat dengan menggunakan \\
& kendaraan hi-lift truck/ kijang \\
& box. \\
\hline
\end{tabular}

Deskripsi produk yang dilakukan oleh tim HACCP sebagian besar sudah sesuai dengan SNI 01-4852-1998 yang menyebutkan bahwa deskripsi produk merupakan penjelasan lengkap dari produk mengenai komposisi, struktur fisika/kimia, perlakuan-perlakuan, pengemasan, kondisi penyimpanan, dan daya tahan serta metode pendistribusiannya. Namun PT.X tidak mencantumkan struktur fisika/kimia menu daging rendang. Struktur fisika dapat berupa rasa, bentuk, dan tampilan secara organoleptik lainnya. Struktur kimia termasuk Aw, $\mathrm{pH}$, dll. juga belum dideskripsikan.

\section{Diagram Alir Proses Produksi Menu Daging Rendang}

Diagram alir yang menggambarkan seluruh proses produksi disusun oleh tim HACCP. Diagram alir dapat mempermudah tim HACCP dalam melaksanakan tugasnya dan berfungsi sebagai pedoman proses verifikasi.

Diagram alir harus diverifikasi oleh tim HACCP untuk menguji ketepatan diagram alir proses tersebut. Apabila ada yang kurang tepat, diagram alir harus dimodifikasi (Handayani, 2012). Proses produksi makanan penerbangan yang dilakukan pada suhu rendah dimulai dari penerimaan bahan, penyimpanan, pengemasan, pengaturan dalam baki (meal tray set up), dan proses distribusi (IFSA, 2010).

\section{Identifikasi bahaya}

Prinsip pertama HACCP adalah identifikasi bahaya yang mungkin muncul selama proses produksi menu daging rendang. Identifikasi 
Tabel 1. Identifikasi Bahaya pada Proses Produksi Menu Daging PT. X

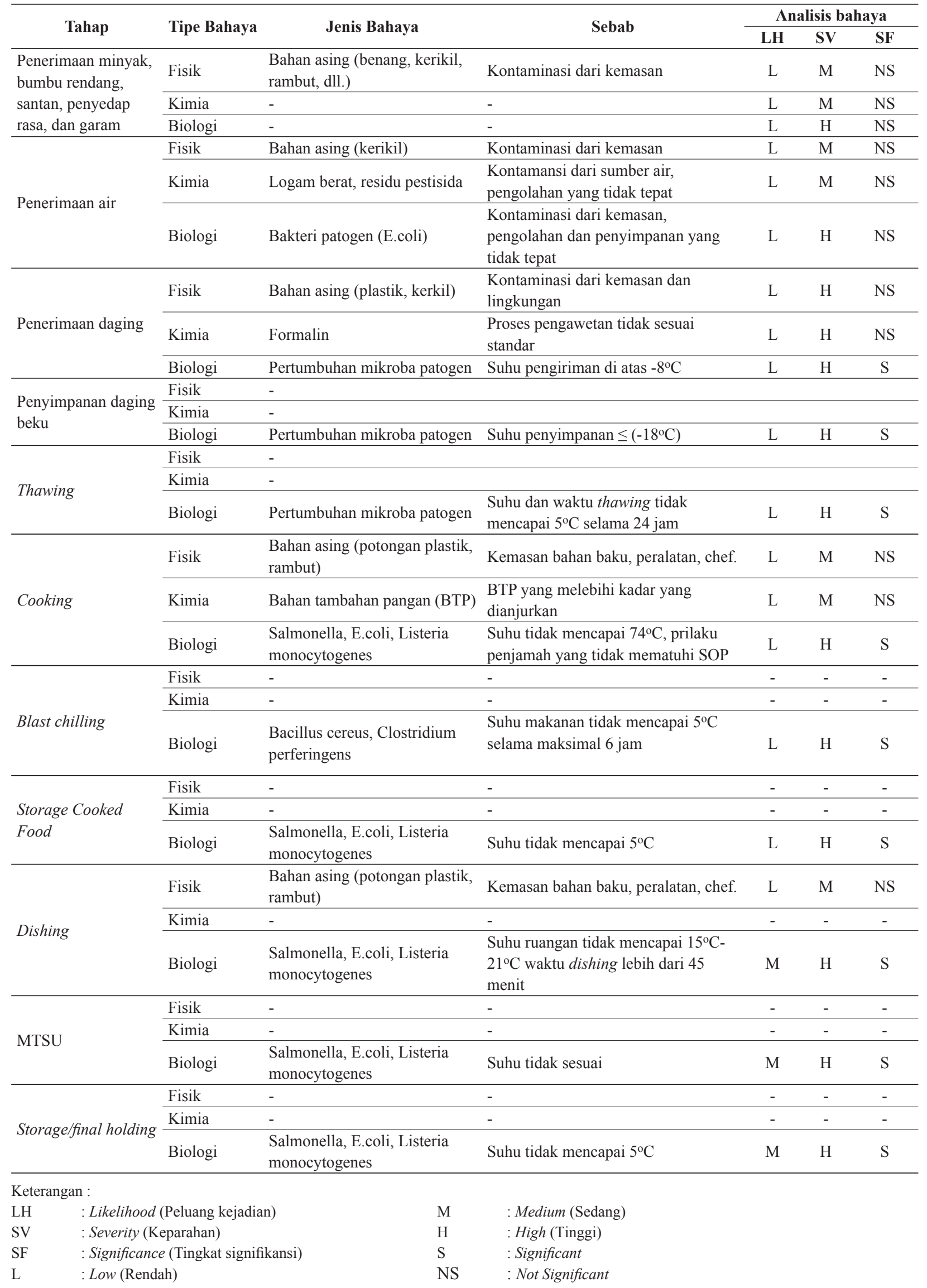


bahaya pada proses menu daging rendang secara keseluruhan sudah sesuai dengan SNI No. 01-48521998. Bahaya yang diidentifikasi pada daging sapi adalah mikroba alami pada daging yaitu jumlah E. coli yang dihitung dengan metode TPC (Total Plate Count). Apabila jumlah bakteri ini melebihi standar, maka akan meningkatan resiko timbulnya penyakit lainnya (Kuntoro dkk., 2012). Potensi bahaya biologi pada daging sapi berupa bakteri Salmonella, $Y$. enterolitica, L. monocytogenes, $S$. aureus, dan $C$. perferingens. Bahaya kimia pada daging dapat berupa formalin, dan bahaya fisik berupa kerikil (Puspitasari, 2015).

Identifikasi bahaya penting dilakukan pada setiap tahapan proses produksi. Bahaya yang signifikan dan tindakan pencegahan harus diidentifikasi. Bahaya yang signifikan akan dijadikan pertimbangan dalam penentuan CCP (Handayani, 2012).

\section{Penentuan CCP dan Batas Kritisnya}

Prinsip HACCP yang kedua adalah penentuan CCP (Critical Control Point). Penentuan CCP dapat dilakukan dengan menggunakan pohon keputusan. Batas kritis adalah sebuah titik kendali yang dilakukan untuk menghilangkan bahaya atau menurunkannya hingga batas aman (Afrianto, 2008). Batas kritis harus ditetapkan secara spesifik dan divalidasi terlebih dahulu. Kriteria yang sering digunakan sebagai batas kritis adalah hasil pengukuran suhu, waktu, tingkat kelembaban, $\mathrm{pH}$, Aw, kandungan klorin, tekstur, dan kenampakan visual. (Afrianto, 2008). Penentuan CCP dan batas kritis pada tiap CCP nya ditunjukkan pada Tabel 2.

Receiving ditetapkan sebagai CCP 1 karena daging dan bahan lainnya mengalami mobilisasi dari pemasok dan tidak ada kendali dari pemasok. Daging sapi berpotensi mengalami kontaminasi mikrobiologi yang berasal dari pekerja dan lingkungan yang tidak higienis (Pupitas, dkk., 2016). PT. X telah menggunakan checklist terkait spesifikasi yang harus dipenuhi, yaitu suhu, kenampakan fisik, dan kandungan TPC harus sesuai dengan SNI karkas daging. Pengujian kandungan TPC dilakukan sebelum kerjasama dengan pemasok dilakukan. Jika daging tidak memenuhi spesifikasi tersebut, maka daging harus
Tabel 2. Penentuan CCP dan batas kritisnya

\begin{tabular}{|c|c|c|}
\hline CCP & Proses & Batas Kritis \\
\hline $\mathrm{CCP} 1$ & Receiving & $\begin{array}{l}\text { Suhu daging }-8^{\circ} \mathrm{C} \text { atau dalam } \\
\text { bentuk frozen } \\
\text { Suhu bumbu rendang jadi } 5^{\circ} \mathrm{C} \\
\text { (Chilled) }\end{array}$ \\
\hline $\mathrm{CCP} 2$ & Storing & $\begin{array}{l}\text { Suhu freezer } \leq-18^{\circ} \mathrm{C} \\
\text { Suhu chiller } 0^{\circ} \mathrm{C}-5^{\circ} \mathrm{C}\end{array}$ \\
\hline $\mathrm{CCP} 3$ & Cooking & Suhu inti daging $74^{\circ} \mathrm{C}$ \\
\hline $\mathrm{CCP} 4$ & $\begin{array}{l}\text { Blast } \\
\text { chilling }\end{array}$ & $\begin{array}{l}\text { Suhu blast chiller }-5^{\circ} \mathrm{C}-0^{\circ} \mathrm{C} \\
\text { selama } 4 \text { jam hingga suhu } \\
\text { makanan } 5^{\circ} \mathrm{C} \text {. } \\
\text { Jika belum mencapai } 5^{\circ} \mathrm{C} \text {, } \\
\text { ditambah } 2 \text { jam }\end{array}$ \\
\hline CCP 5 & $\begin{array}{l}\text { Dishing/ } \\
\text { portioning }\end{array}$ & $\begin{array}{l}\text { Suhu ruangan } \leq 5^{\circ} \mathrm{C} \text { maka } \\
\text { proses kontrol berlaku seperti } \\
\text { untuk penyimpanan chiller. } \\
\text { Jika suhu ruang }>5^{\circ} \mathrm{C} \text { dan } \\
\leq 15^{\circ} \mathrm{C} \text { maka proses dishing } \\
\text { dilakukan maksimal } 90 \text { menit } \\
\text { dan suhu ruang dikontrol } \\
\text { minimum } 2 \text { kali sehari. } \\
\text { Corrective action dilakukan } \\
\text { jika suhu ruangan }>15^{\circ} \mathrm{C} \text {. } \\
\text { Jika suhu ruangan }>21^{\circ} \mathrm{C} \\
\text { maka proses dishing dilakukan } \\
\text { maksimal } 45 \text { menit dan suhu } \\
\text { permukaan tidak melebihi } \\
15^{\circ} \mathrm{C}\end{array}$ \\
\hline
\end{tabular}

dikembalikan kepada pemasok. Penggunaan checklist, penyortiran, dan penanganan bahan yang tepat dapat mengurangi adanya risiko bahaya (Andonie, 2012).

Batas kritis receiving yang harus dipenuhi bahan beku (frozen) di PT. X adalah $-8^{\circ} \mathrm{C}$, sedangkan untuk bumbu rendang adalah $5^{\circ} \mathrm{C}$ (Chilled). Suhu penyimpanan daging beku harus dipertahankan pada suhu $\leq-18^{\circ} \mathrm{C}$ (Afrianto, 2008). Karkas daging beku yang disimpan pada suhu $-6^{\circ} \mathrm{C}$ hingga $-17^{\circ} \mathrm{C}$ dapat bertahan selama $3-12$ bulan (Gustiani, 2009). Bumbu rendang instan dan santan dalam kemasan disimpan di dalam chiller dengan suhu $0^{\circ} \mathrm{C}-5^{\circ} \mathrm{C}$. Bahan lainnya seperti minyak goreng, bumbu serba guna, dan garam disimpan di gudang dengan suhu ruang.

Sehari sebelum dimasak, daging sapi yang masih beku harus di thawing terlebih dahulu. Thawing dilakukan untuk mencairkan daging. Thawing dilakukan dengan mendiamkan daging 
di chiller bersuhu $1{ }^{\circ} \mathrm{C}-4^{\circ} \mathrm{C}$ selama $12-24$ jam (Andonie, 2012). Setelah itu, daging dipotong dadu dan dimasukkan ke dalam chiller jika tidak langsung digunakan. Daging yang telah dipotong dan dimasukkan ke dalam chiller harus segera dimasak.

Langkah pertama pemasakan daging rendang adalah dengan menumis bumbu rendang instan di dalam minyak panas. Setelah bumbu berubah warna dan tercium bau harum, ditambahkan air, diaduk, dan dibiarkan hingga mendidih. Setelah mendidih, potongan daging dan santan dimasukkan, lalu panci ditutup selama 30 menit. Saat daging hampir matang, ditambahkan monosodium glutamate (MSG) dan garam, kemudian dimasak lagi hingga matang. Terdapat potensi bahaya yang signifikan yang dapat dihilangkan selama proses pemasakan bahan baku beku, sehingga ditetapkan sebagai CCP (Afrianto, 2008). Daging sapi dimasak pada suhu $74^{\circ} \mathrm{C}$ selama 2 jam. Proses cooking dimulai dengan merebus daging Perebusan ditujukan untuk membunuh mikroba mesotermik. Lama pemasakan di atas 15 menit dapat mengurangi risiko pencemaran kembali oleh mikroba setelah proses pengolahan makanan selesai (Dewi, 2015). Pemasakan daging pada suhu $70^{\circ} \mathrm{C}$ selama 2 menit dapat membunuh kandungan bakteri E. coli dan patogen lain (Afrianto, 2008). Rendang yang telah matang dimasukkan ke dalam blast chiller dengan suhu $-5^{\circ} \mathrm{C}$ sampai $0^{\circ} \mathrm{C}$ selama maksimal 4 jam, hingga suhu makanan tercapai $5^{\circ} \mathrm{C}$, jika suhu daging rendang belum mencapai $5^{\circ} \mathrm{C}$, penyimpanan di dalam blast chiller ditambah 2 jam. Daging rendang yang telah memiliki suhu $5^{\circ} \mathrm{C}$ dimasukkan ke dalam chiller dengan suhu $0^{\circ} \mathrm{C}$ sampai $5^{\circ} \mathrm{C}$ yang disusun di loyang lebar. Masa simpan makanan di dalam chiller sebelum melalui tahap dishing adalah maksimal 2 hari.

Wadah yang akan digunakan untuk proses dishing harus sudah disanitasi. Kondisi kebersihan yang ketat harus diterapkan pada tahapan dishing. Daging rendang dikeluarkan dari chiller dan dikemas bersama dengan nasi sesuai dengan golden sampel atau contoh makanan yang sesuai dengan standar. Dishing dilakukan selama maksimal 45 menit dengan suhu ruang $16^{\circ} \mathrm{C}$ dan suhu makanan maksimal $15^{\circ} \mathrm{C}$. Hal ini dilakukan karena setelah 45 menit berada pada medium atau lingkungan yang menguntungkan, bakteri akan mengalami fase $\log$ atau pertumbuhan yang sangat cepat (Hamdiyati, 2011).

Proses pengemasan (dishing) pangan siap santap dianggap sebagai CCP karena proses pengemasan ini sangat sensitif terhadap pertumbuhan mikroba (Afrianto, 2008). Daging rendang yang telah di dishing selanjutnya diberi label. Setelah itu, makanan dibawa ke MTSU (Meal Tray Set Up) untuk kemudian dilakukan holding atau pengiriman menu ke bandara dengan menggunakan truck container. Suhu holding room maksimal $5^{\circ} \mathrm{C}$, jika lebih harus ditambah dry ice. Standar suhu holding room telah sesuai dengan suhu penyimpanan dingin yang baik, yaitu $-1^{\circ} \mathrm{C}-5^{\circ} \mathrm{C}$ (Afrianto, 2008).

\section{Monitoring dan Tindakan Koreksinya}

Prinsip yang keempat dan kelima adalah monitoring dan tindakan koreksi. Pemantauan merupakan kegiatan rutin berupa pengukuran atau pengamatan pada tiap CCP dan dibandingkan dengan batas kritisnya. Tindakan koreksi harus dilakukan ketika terdapat penyimpangan atau proses yang melampaui batas kritis (Wardani, 2015). Kegiatan monitoring dilakukan agar CPP berada di bawah batas kritis (Renosori, dkk., 2012).

Tindakan koreksi dilakukan jika proses produksi tidak sesuai standar. Berdasarkan hasil observasi, monitoring suhu kematangan daging rendang tidak dilakukan dengan mengukur suhu inti daging menggunakan termometer probe.

Juru masak memonitoring tingkat kematangan daging secara organoleptik. Pemasakan daging rendang dilakukan selama \pm 45 menit hingga tekstur dagingnya empuk, sehingga secara otomatis suhu inti pemasakan daging telah tercapai. Juru masak membuka kemasan santan kemasan di dekat panci sehingga potongan kemasan santan masuk ke dalam panci dan diambil dengan tangan yang pada saat itu tidak memakai sarung tangan. Sebaiknya santan disiapkan terlebih dahulu di wadah tersendiri. Pembukaan kemasan dilakukan jauh dari panci masak untuk mencegah adanya foreign object yang masuk ke dalam makanan. Karena foreign object dapat menjadi sumber kontaminasi. 
Tabel 3. Monitoring Suhu dan Tindakan Koreksi pada Proses Produksi Menu Daging Rendang

\begin{tabular}{|c|c|c|c|}
\hline Proses & Jenis & Standar & Tindakan koreksi \\
\hline \multirow[b]{2}{*}{ Receiving } & $\begin{array}{l}\text { Daging sapi } \\
\text { (Frozen) }\end{array}$ & $\begin{array}{l}\text { Suhu }-8^{\circ} \mathrm{C} \text { atau dalam } \\
\text { bentuk frozen }\end{array}$ & $\begin{array}{l}\text { Daging ditolak dan dikembalikan ke supplier dengan } \\
\text { menyertakan BAP (Berita Acara Penolakan) }\end{array}$ \\
\hline & $\begin{array}{l}\text { Bumbu } \\
\text { rendang jadi } \\
\text { (chilled) }\end{array}$ & Suhu $5^{\circ} \mathrm{C}($ Chilled $)$ & $\begin{array}{l}\text { Bumbu rendang jadi ditolak dan dikembalikan ke supplier } \\
\text { dengan menyertakan BAP (Berita Acara Penolakan) }\end{array}$ \\
\hline \multirow[b]{2}{*}{ Storing } & Chiller & $0^{\circ} \mathrm{C}-5^{\circ} \mathrm{C}$ & $\begin{array}{l}\text { Jika suhu chiller lebih dari } 5^{\circ} \mathrm{C} \text { selama lebih dari } 4 \text { jam, maka } \\
\text { periksa makanan secara random. } \\
\text { Jika rata- rata suhu makanan }>8^{\circ} \mathrm{C} \text { maka pindahkan makanan } \\
\text { ke chiller lain yang masih memiliki suhu sesuai dengan standar. } \\
\text { Segera perbaiki chiller tersebut. }\end{array}$ \\
\hline & Freezer & $\leq-18^{\circ} \mathrm{C}$ & $\begin{array}{l}\text { Jika suhu freezer lebih dari }-15^{\circ} \mathrm{C} \text { selama lebih dari } 4 \text { jam maka } \\
\text { cek suhu makanan } \\
\text { Jika makanan masih keras dan beku serta tidak ada tanda- } \\
\text { tanda thawing, pindahkan makanan ke freezer lain yang masih } \\
\text { memiliki suhu sesuai dengan standar. Segera perbaiki freezer } \\
\text { tersebut. } \\
\text { Jika makanan telah lunak atau menunjukkan tanda- tanda } \\
\text { thawing, maka makanan harus segera di thawing dan digunakan } \\
\text { sesuai prosedur thawing. }\end{array}$ \\
\hline Cooking & & Suhu inti daging $74^{\circ} \mathrm{C}$ & $\begin{array}{l}\text { Jika suhu inti daging belum tercapai, dilakukan pemasakan lagi } \\
\text { hingga suhu standar tercapai. }\end{array}$ \\
\hline Blast chilling & & $\begin{array}{l}\text { Suhu inti daging rendang } \\
5^{\circ} \mathrm{C}\end{array}$ & $\begin{array}{l}\text { Jika setelah penambahan } 2 \text { jam suhu inti daging rendang tidak } \\
\text { mencapai } 5^{\circ} \mathrm{C} \text {, maka daging rendang harus dibuang. }\end{array}$ \\
\hline \multicolumn{2}{|c|}{ Dishing/portioning } & $\begin{array}{l}\text { Suhu ruangan antara } \\
5^{\circ} \mathrm{C}-15^{\circ} \mathrm{C}\end{array}$ & Jika suhu ruangan $>15^{\circ} \mathrm{C}$, maka $\mathrm{AC}$ harus segera diperbaiki. \\
\hline
\end{tabular}

Suhu chiller tidak boleh lebih dari $8^{\circ} \mathrm{C}$, karena pada suhu di atas $8^{\circ} \mathrm{C}$, bakteri akan mengalami pertumbuhan yang paling cepat. Penyimpanan karkas pada suhu chilled $\left(\leq 3{ }^{\circ} \mathrm{C}\right)$ dapat mendormankan bakteri dan mengurangi jumlah bakteri patogen di dalam karkas daging (Sutrisno, 2013). Suhu penyimpanan makanan yang aman adalah pada suhu $\leq 5^{\circ} \mathrm{C}$ atau $\geq 60^{\circ} \mathrm{C}$. Suhu $5^{\circ} \mathrm{C}-60^{\circ} \mathrm{C}$ merupakan danger zone, yaitu suhu yang memungkinkan mikroba berkembang biak dengan cepat dan menyebabkan kebusukan atau keracunan pangan (Handayani, 2012).

Blast chilling merupakan penurunan suhu makanan secara cepat dari $70^{\circ} \mathrm{C}$ ke $3{ }^{\circ} \mathrm{C}$ selama 90 menit yang bertujuan untuk membunuh bakteri yang tahan di suhu dingin dan suhu panas sekaligus sebelum bakteri berkembang biak lebih banyak lagi. Suhu inti pemasakan daging adalah $74^{\circ} \mathrm{C}$ untuk memastikan bahwa kandungan mikroba di dalam daging telah mati atau berkurang pada tingkat yang aman (IFSA, 2010).

\section{Verifikasi Mikrobiologi Pangan}

Prinsip HACCP yang keenam adalah verifikasi. Kegiatan verifikasi yang dilakukan oleh PT.X sudah sesuai dengan SNI No. 01-4852-1998, yaitu mencakup peninjauan kembali sistem pencatatan HACCP, peninjauan kembali penyimpangan dan disposisi produk, dan memastikan CCP memenuhi batas kritisnya (BSN, 1998). Verifikasi dilakukan untuk memastikan sistem HACCP telah berjalan dengan benar sehingga mampu menghasilkan mutu produk yang berkualitas (Sutrisno, 2013). Kegiatan verifikasi terdiri dari empat kegiatan, yaitu validasi HACCP, meninjau hasil pemantauan, pengujian produk, dan auditing (Renosori, dkk., 2012).

Kegiatan verifikasi mikrobiologi menu daging rendang di PT.X dilakukan secara internal oleh 


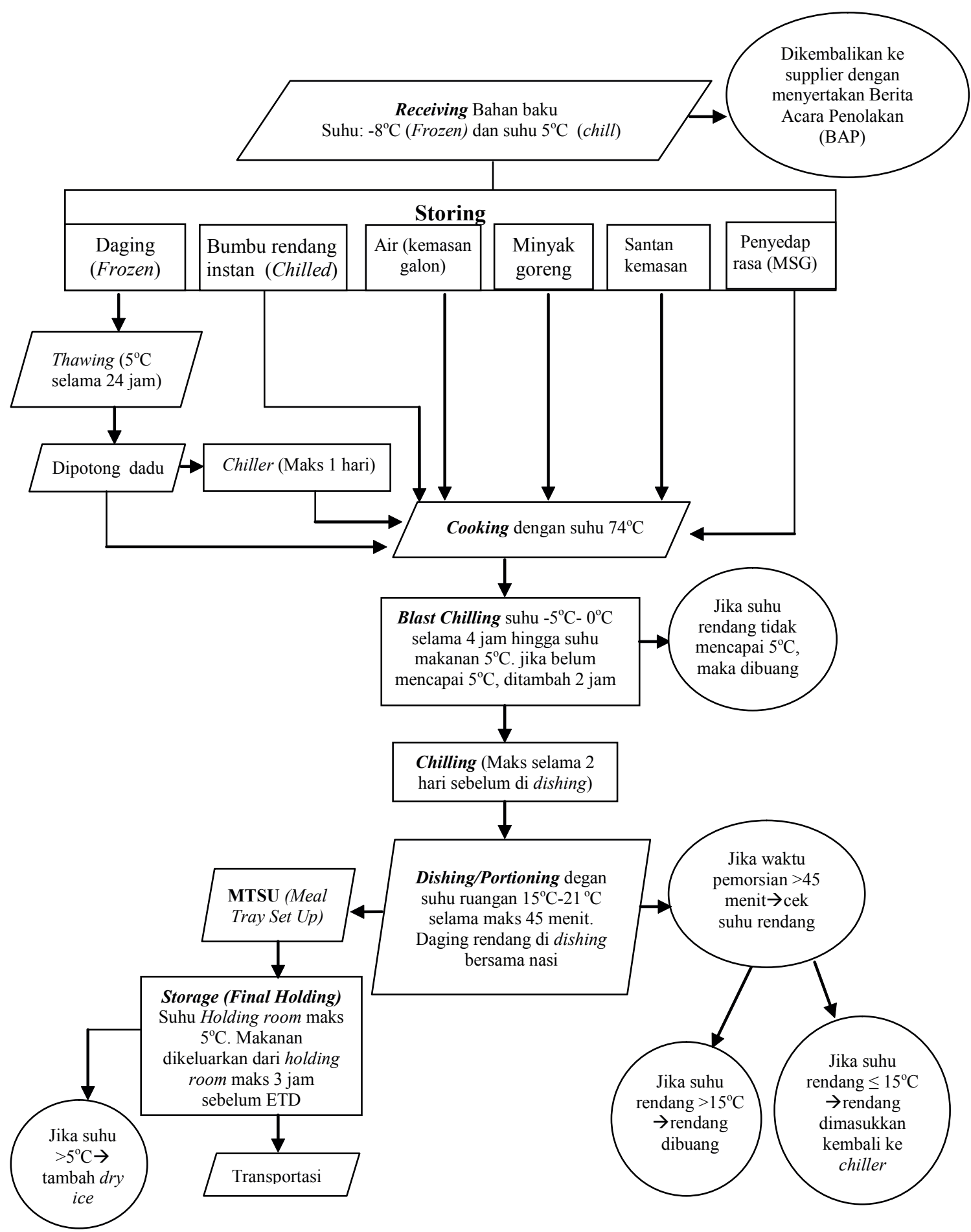

Gambar 1.Diagram Alir Proses Produksi Menu Daging Rendang di PT. X

departemen QHSE. Kegiatan verifikasi dilakukan sebelum menu daging rendang dikirim ke maskapai pemesan. Menu rendang yang telah di dishing diambil satu porsi sebagai sampel kemudian diuji kandungan bakterinya. Jenis bakteri yang diuji adalah enterobacter, E. coli, Staphylococcus aureus, Salmonella sp, Bacillus cereus, dan lainnya dengan metode TPC. Apabila hasil pemeriksaan menunjukkan keberadaan bakteri patogen tertentu atau jumlahnya melebihi ambang batas, maka segera dilakukan tindakan perbaikan berupa penarikan dan pemusnahan produk. 


\section{Dokumentasi dan Pencatatan}

Prinsip HACCP yang ketujuh adalah dokumentasi dan pencatatan. Dokumentasi HACCP meliputi pendataan tertulis semua langkah HACCP yang dilakukan agar dapat dilakukan pemeriksaan ulang dalam periode waktu tertentu (Wardani, 2015). Penerapan sistem HACCP pada menu daging rendang didokumentasikan mulai dari receiving bahan baku, penyimpanan bahan, proses pemasakan, pemorsian, dan penyimpanan akhir. Pada dokumen HACCP terdapat form Hazard Analysis Checksheet untuk menu rendang yang berisi analisis bahaya fisika, kimia, dan biologi pada setiap proses produksi daging rendang. Analisis lain yang harus dicatat yaitu penyebab bahaya, tingkat keparahan, dan tindakan kontrol atau pencegahan. Pencatatan pada tindakan verifikasi dilakukan dengan mencatat hasil kandungan bakteri dalam menu daging rendang dan hasil meal check yang dilakukan setiap hari sebelum makanan dikirim, yaitu meliputi berat, rasa, dan tekstur.

\section{KESIMPULAN DAN SARAN}

PT. X telah menerapkan sistem keamanan pangan HACCP sesuai dengan SNI No. 01-4852-1998 tentang sistem analisis bahaya dan pengendalian titik kritis (HACCP) serta pedoman penerapannya. Penerapan HACCP dalam proses produksi menu daging rendang di PT.X adalah dengan mengontrol suhu dan waktu selama proses produksi untuk mencegah pertumbuhan mikroba dan mencegah kerusakan makanan, sehingga menu daging rendang yang diproduksi oleh PT. X aman dikonsumsi.

Saran yang dapat diberikan kepada PT. X adalah sebaiknya monitoring dan pencatatan suhu makanan pada proses blast chilling perlu dilakukan secara rutin untuk mengetahui apakah suhu pendinginan telah tercapai. Proses blast chilling merupakan CCP 4, sehingga apabila suhu dan waktu yang telah ditentukan tidak tercapai, harus dilakukan tindakan koreksi.

Pencatatan waktu dan suhu awal dan akhir pada proses dishing perlu dilakukan secara rutin untuk memantau apakah waktu dan suhu yang ditentukan telah tercapai. Jika tidak dilakukan pencatatan waktu dan suhunya maka dapat memungkinkan waktu pemorsian lebih dari 45 menit dan suhunya $>5^{\circ} \mathrm{C}$. Dishing merupakan CCP 5, sehingga apabila suhu dan waktunya tidak tercapai, harus dilakukan tindakan koreksi.

Sebaiknya pembukaan kemasan bahan masak dilakukan di tempat yang jauh dari panci untuk menghindari adanya kontaminasi foreign object berupa potongan kemasan yang masuk ke dalam panci saat proses pemasakan.

\section{DAFTAR PUSTAKA}

Afrianto, E. (2008). Pengawasan mutu bahan/ produkpangan. Jakarta: Departemen Pendidikan Nasional.

Andonie, R. (2012). Kajian pelaksanaan keamanan makanan berdasarkan HACCP di MV. Samudera 02 Milik PT Karya Jaya Samudera (Skripsi yang tidak dipublikasi), Universitas Indonesia, Depok. Diakses dari http://lib.ui.ac.id/abstrakp df?id=20314741\&lokasi=lokal

Badan Standardisasi Nasional.(1998). SNI Nomor 01-4852-1998 tentang Sistem Analisis Bahaya dan Pengendalian Titik Kritis (HACCP) serta pedoman penerapannya. Jakarta: Badan Standardisasi Nasional.

Dewi, L.M. (2015). Evaluasi bahaya mikrobiologi pada ayam goreng laos melalui prinsipprinsip HACCP di Instalasi Gizi RS PKU Muhammadiyah Surakarta. (Skripsi yang tidak dipublikasi), Universitas Muhammadiyah, Surakarta. Diakses dari http://eprints.ums. ac.id/39010/1/PUBLIKASI\%20KARYA\%20 ILMIAH.pdf.

Fitriana, F.I. (2012). Pengaruh kenaikan suhu makanan terhadap kenaikan jumlah TPC pada makanan penerbangan (Skripsi, yang tidak dipublikasikan), Universitas Indonesia, Depok. Diakses dari lib.ui.ac.id/ file file $=$ digital/20318948-S-PDF.

Gustiani, E. (2009). Pengendalian cemaran mikroba pada bahan asal ternak (daging dan susu) mulai peternakan sampai dihidangkan. Jurnal Litbang Pertanian, 28(3), 96-100. Diakses dari library. um.ac.id/majalah/printmajalah.php/41369. html

Hamdiyati, Y.(2011). Petumbuhan dan pengendalian mikroorganisme II. Bandung: Universitas Pendidikan Indonesia. 
Handayani, T. (2012). Kajian sistem keamanan pangan untuk industri jasa boga, studi kasus pada PT. ELN, Jakarta (Tesis yang tidak dipublikasikan), Institut Pertanian Bogor, Bogor. Diakses dari http://repository.ipb.ac.id/jspui/bit stream/123456789/59440/1/2012tha.pdf.

Huda, S.E. (2016). Santap nasi lauk cicak, penumpang pesawat keracunan. Diakses dari https://www.dream.co.id/news/santap-nasilauk-cicak-penumpang-airasia-keracunan160408w.html

International Flight Service Association. (2010). World food safety guideline for airline catering $3^{\text {rd }}$ version. Atlanta, GA: International Flight Services Association.

Kuntoro, Bambang, Maheswari, Rarah, R.A., \& Nuraini, H. (2012). Hubungan penerapan SSOP terhadap mutu daging ditinjau dari tingkat cemaran bakteri. Jurnal Ilmiah Ilmu- Ilmu Peternakan, 15(2), 70-80. Diakses dari https:// online-journal.unja.ac.id/index.php/jiip/article/ view/1794/1178.

Pupitas, D., Santosa, V., Rahardjo, M., Tjahyono, J. D., 2, Sirenden, M.T., \& Seilatuw M.M. (2016). Penerapan sistem HACCP dan GMP pada proses pembuatan abon di Industri ABON45 di Kabupaten Semarang. Seminar Nasional Pengabdian Kepada Masyarakat, 363-372. Diakses dari http://docplayer.info/46596563Penerapan-sistem-haccp-dan-gmp-padaproses-pembuatan-abon-di-industri-abon45di-kabupaten-semarang.html

Puspitasari, F.D. (2015). Tinjauan HACCP makanan rendang pada salah satu rumah makan padang di Kentungan, Depok, Sleman (Skripsi yang tidak dipublikasi), Universitas Gajah Mada, Yogyakarta. Diakses dari http://etd.repository. ugm.ac.id/index.php?act=view\&buku_ id $=90955 \&$ mod $=$ penelitian_detail\&sub $=$ Penel itianDetail\&typ $=\mathrm{html}$

Ratnaningsih, N. (2010). Mikrobiologi Pangan. Yogyakarta: Jurusan PTBB, FT UNY.

Renosori, P., Ceha, R., \& Utari, R. (2012). Upaya meningkatkan pengendalian kualitas keamanan pangan UKM melalui penerapan hazard analysis critical control point (HACCP). Prosiding SNaPP 2012: Sains, Teknologi, dan Kesehatan. Diakses dari http://prosiding.lppm.unisba.ac.id/ index.php/Sains/article/view/315/pdf.

Sadek, N.F. (2010). Penerapan sistem HACCP (hazard analysis critical control point) pada warung tegal dan pembuatan modul pelatihannya sebagai salah satu bentuk CSR (corporate social responsibility) PT Bintang Toedjoe Jakarta (Skripsi yang tidak dipublikasikan), Institut Pertanian Bogor, Bogor. Diakses dari http://repository.ipb.ac.id/ bitstream/handle/123456789/59853/F10nfs. pdf? sequence $=1 \&$ isAllowed $=\mathrm{y}$

Sekretaris Negara RI. (2004). Peraturan pemerintah nomor 28 tahun 2004 tentang keamanan, mutu, dan gizi pangan. Jakarta: Kementrian Sekretariat Negara RI.

Sutrisno, A. (2013). Analisis strategi penerapan sistem manajemen keamanan pangan haccp di PT. Sierad produce tbk. Parung (Skripsi yang tidak dipublikasikan), Institut Pertanian Bogor, Bogor. Diakses dari http://repository.ipb.ac.id/ handle/123456789/63844.

Wardani, A.K. (2015). Efektivitas pelaksanaan quality control pada bagian produksi di PT. Indohamafish di Pengambengan. Jurnal Pendidikan Ekonomi Undiksha, 5(1). Diakses dari http://ejournal.undiksha.ac.id/index.php/ JJPE/article/view/5092. 